\title{
GLAUBER ROCHA DESCOBRE A AMAZÔNIA: DISCURSO \\ E REPRESENTAÇÕES SOCIAIS NO DOCUMENTÁRIO \\ AMAZONAS, AMAZONAS
}

GLAUBER ROCHA DISCOVERS THE AMAZON: SPEECH AND SOCIAL REPRESENTATIONS IN THE DOCUMENTARY

AMAZONAS, AMAZONAS

\author{
Rosiel do Nascimento Mendonça \\ Sérgio Ivan Gil Braga \\ UFAM
}

\section{Resumo}

O artigo faz uma análise do discurso fílmico do documentário de curta-metragem Amazonas, Amazonas, dirigido pelo cineasta baiano Glauber Rocha entre os anos de 1965 e 1966. Para isso, recorremos a fontes documentais e bibliográficas no intuito de reconstituir a experiência do diretor na região e as condições sociais de produção do filme, buscando identificar que representações ele faz do Amazonas - e da região amazônica, em sentido mais amplo.

\section{Palavras-chave:}

Cinema; Amazônia; Amazonas;

Cinema Novo; Glauber Rocha.

\section{INTRODUÇÃO}

O cinema nem sempre ocupou posição de destaque entre as artes. Inicialmente considerada uma atração pitoresca e divertimento de feira, a invenção atribuída aos irmãos Lumière demorou a ser reconhecida como linguagem e expressão criativa, o que só veio a acontecer com o desenvolvimento de uma estrutura narrativa propriamente fílmica. Ainda assim, seu valor como fonte documental seria negligenciado pelo menos até meados do século XX. Até então, as fontes históricas eram extremamente hierarquizadas, e apenas os documentos oficiais escritos eram considerados suficientemente autênticos e confiáveis para a reconstituição do fato histórico.

\section{Abstract}

The article makes an analysis of the filmic discourse of the short documentary Amazonas, Amazonas, directed by Glauber Rocha between the years 1965 and 1966. For this, we used documentary and bibliographical sources in order to reconstitute the experience of the director in the region and the social conditions of production of the film. We also try to identify wich representations does the film make of Amazonas and the Amazon region.

Keywords:

Cinema; Amazônia; Amazonas; Cinema Novo; Glauber Rocha.

O filme, portanto, estava em dupla desvantagem diante dessa visão positivista: por exigir um esquema de interpretação mais complexo, que levasse em conta imagem e discurso verbal, e por ser fruto de um processo de edição e montagem, o que poderia sugerir manipulação e falseamento da realidade (NÓVOA, 2012).

O cenário mudou a partir dos anos 60, quando novas concepções e paradigmas ganharam espaço no campo das Ciências Sociais, com reflexos também na História. As imagens do cinema deixaram de ser vistas como meramente ilustrativas, ligadas unicamente ao entretenimento, e começaram a ser valorizadas pelos rastros e vestígios que 
poderiam fornecer sobre a sociedade e o tempo que as produziu. Termos como "cinema-história", cunhado por Marc Ferro nesse período, surgiram com o intuito de dar ao cinema o devido valor, tanto como fonte de conhecimento histórico, quanto como agente transformador dessa mesma História.

É sob essa perspectiva interdisciplinar que nos propusemos a analisar o documentário Amazonas, Amazonas ${ }^{1}$, dirigido pelo cineasta baiano Glauber Rocha em 1965 e lançado no ano seguinte. Com cerca de 15 minutos de duração, o curta-metragem foi encomendado pelo Governo do Amazonas, que desejava divulgar os potenciais socioeconômicos do estado.

$\mathrm{Na}$ ocasião de sua viagem ao Amazonas, Glauber tinha 26 anos e já era reconhecido internacionalmente pelo filme Deus e o Diabo na Terra do Sol, indicado à Palma de Ouro do Festival de Cannes de 1964. Em Manaus, o diretor fez não só o seu primeiro filme em cores e primeiro documentário, mas também uma de suas únicas obras institucionais para fins de propaganda, na contramão do cinema autoral e revolucionário que defendia como um dos articuladores do movimento do Cinema Novo. Somem-se a isso as circunstâncias pessoais em que Glauber filmou Amazonas, Amazonas, pois havia acabado de sair da prisão depois de se envolver num protesto contra a ditadura militar, no Rio de Janeiro.

Chama a atenção o fato de Amazonas, Amazonas e a história por trás dessa produção ainda serem um episódio praticamente desconhecido e pouco estudado da trajetória de Glauber, que é considerado por muitos como o mais importante cineasta brasileiro. Por outro lado, na biografia que João Carlos Teixeira Gomes (1997) escreveu sobre o amigo e conterrâneo, encontramos a sugestão de que a experiência no Amazonas teria sido equivalente às andanças que Glauber empreendeu pelo Nordeste, no início dos anos 1960, e que acabaram inspirando a concepção de Deus e o Diabo.

Segundo o autor, o cineasta encarava essas viagens como uma oportunidade de ampliar sua visão sobre o País: "A tudo enfrentava com obstinação, levado pelo desejo de conhecer, em sua diversificação humana, social e econômica, a realidade do Brasil" (GOMES, 1997, p. 427). Reservadamente, porém, o diretor admitiu sua completa ignorância sobre o que deveria documentar no Amazonas, como ficou registrado em uma das cartas que ele escreveu, na época, ao produtor do filme, Luiz Augusto Mendes: “... $\mathrm{Eu}$, sem conhecer porra nenhuma aqui, tenho que fazer um grande filme sobre o Amazonas" (ROCHA, 1997, p. 36).

Diante disso, buscamos nos aprofundar em questões latentes que cercam Amazonas, Amazonas, na tentativa de responder às seguintes interrogações: quais esquemas interpretativos Glauber acionou no processo de autoria do documentário? Com que "discursos socialmente disponíveis" (STAM, 2013, p. 211) o filme dialoga, tendo em vista o interesse que a Amazônia sempre despertou em homens da ciência e das letras? Que discursos o filme (re)elabora? Que representações sociais ele faz da região e da sua população?

A opção metodológica que adotamos nessa análise é guiada por Pierre Bourdieu (1996), que propõe a interpretação de obras culturais a partir do microcosmo social em que são produzidas; e por José D'Assunção Barros (2012), que defende uma análise fílmica multidisciplinar, capaz de abarcar a complexidade discursiva das obras, bem como seus elementos intencionais e não intencionais. Afinal, entendemos não ser possível ignorar o contexto de produção de Amazonas, Amazonas durante esse processo, pois "não importa se o filme pretende ser um retrato, uma intriga autêntica ou pura invenção, sempre estará sendo produzido dentro da história e sujeito às dimensões sociais e culturais que decorrem dela" (BARROS, 2012, p. 71).

Ao fim do percurso, esperamos poder ampliar o rol de informações disponíveis sobre Amazonas, Amazonas, uma obra ainda negligenciada quando se considera a filmografia glauberiana, ao mesmo tempo em que pretendemos oferecer ao campo cinematográfico uma visão crítica a respeito de filme tão peculiar.

\section{CINEMA A SERVIÇO DO ESTADO}

Com o declínio do Ciclo da Borracha, a partir da primeira década do século $X X$, o Amazonas passou a experimentar uma renitente sensação de abandono econômico e isolamento cultural em relação ao restante do Brasil. Isso porque, de acordo com Djalma Batista, a goma elástica 
significou não só um marco da história amazônica, mas de sua psicologia, como uma "neurose obsessiva". O espírito pós-derrocada, como consequência, distinguiu-se por um mal-estar contagiante que repercutiu em todas as esferas sociais, um misto de "esperanças indefinidas e desesperos profundos" (BATISTA, 2007, p. 34).

Nos anos 1960, período em que Narciso Lobo (1994) situa a sua obra A tônica da descontinuidade, o marasmo e o provincianismo ainda reinavam em Manaus, uma cidade até então "esquecida no coração da floresta". Depois de décadas convivendo com as consequências da crise do sistema extrativista, e de sucessivas tentativas e planos de reerguimento econômico, a capital estava prestes a testemunhar o início de um novo ciclo de desenvolvimento. A partir de 1967, a implementação da Zona Franca de Manaus, que representou a efetiva penetração do capital industrial no Amazonas, passou a acenar com promissoras perspectivas econômicas.

Foi em meio a essa conjuntura que o cineasta baiano Glauber Rocha, um dos expoentes do movimento do Cinema Novo, chegou a Manaus, no dia 14 de dezembro de 1965. Ele vinha do Rio de Janeiro na companhia do fotógrafo Fernando Duarte e tinha a missão de rodar um curta-metragem promocional sob encomenda do Governo do Amazonas, então comandado pelo historiador e "amazonólogo" Arthur Reis, burocrata e outsider político alçado ao poder após o golpe militar.

Oficialmente, quem intermediou a contratação do artista foi o diretor do recém-criado Departamento de Turismo e Promoção (Depro), Luiz Maximino de Miranda Corrêa Neto, que havia sugerido em carta ao governador, em setembro daquele ano, a realização de um documentário com o objetivo de divulgar os "aspectos turísticos e econômicos" do Amazonas. Para ele, o investimento se justificava porque o cinema possuía um poder de divulgação e penetração social maior que qualquer outra ferramenta de propaganda disponível, podendo sensibilizar com mais rapidez plateias de todo o mundo para as belezas e potenciais do estado².

Em sua função de embaixador extraoficial do Amazonas, Luiz Maximino viajava com frequência pelas capitais do Sul e Sudeste, como Rio de Janeiro, São Paulo e Porto Alegre, e algumas vezes também para o exterior. Nessas viagens de trabalho, ele costumava se reunir com executivos de companhias aéreas e turísticas estrangeiras, representantes de redes hoteleiras e quem mais se interessasse em fazer negócios no Amazonas. Em carta ao governador Arthur Reis, ele defendeu: "O turismo pode trazer muito dinheiro para o nosso Estado, e canalizar alguns bilhões em investimentos" ${ }^{\prime 3}$.

A realização de um documentário de divulgação do Amazonas estava em sintonia, portanto, com a missão do Depro de conferir uma imagem dinâmica ao estado, então sob o domínio de um governo "revolucionário", patrocinador de uma ideologia de modernização conservadora do Brasil.

A linguagem cinematográfica vinha sendo utilizada na região com esse mesmo intuito promocional desde os primeiros anos do século XX. De acordo com a pesquisadora Selda Vale da Costa (1996), "a propaganda da região, seus rios, florestas, flora e fauna foram o objetivo das primeiras filmagens" (p. 113). Com o advento da crise da borracha, e na tentativa de atrair novamente olhares e investimentos para a região estagnada, os empresários e políticos locais articularam alianças e passaram a investir no cinema como ferramenta de divulgação.

Um caso exemplar foi o do pioneiro Silvino Santos, que produziu uma série de filmes para o empresário J. G. Araújo. Desse contato entre os dois nasceu o documentário No Paiz das Amazonas (1922), que tinha o objetivo de destacar e valorizar os meios de produção e as qualidades econômicas do Amazonas. Levado à Exposição Internacional do Centenário da Independência, realizada no Rio de Janeiro, o filme viria a desfrutar de boa recepção nacional e internacional pelo menos até 1930 , sendo frequentemente exibido em Manaus por ocasião de solenidades ou visitas oficiais. A obra foi recebida com entusiasmo e ufanismo, segundo os registros da época: "O filme serviu a todos os interesses, casando a necessidade regional de integração à nação com o despertar brasileiro do sentido de unidade nacional" (COSTA, 1996, p. 207).

Nos anos 60, não se tratava de uma excepcionalidade a encomenda de um filme com objetivo semelhante a Glauber Rocha. No mesmo período em que o diretor esteve em Manaus, - Departamento de Estradas de Rodagem do Amazonas (DERam) também encomendou dois documentários sobre obras de infraestrutura 
estaduais à empresa J. Borges Filmes Ltda., que tinha um histórico de trabalhos realizados para ministérios e outros governos.

De acordo com Lobo (1994), em anos anteriores, as gestões estaduais vinham se limitando a proporcionar facilidades logísticas a equipes de cinema em passagem pelo Amazonas, cedendo equipamentos e lanchas, mas sem poder de interferência direta no que era produzido. Foi no governo Arthur Reis que o cinema passou a ser efetivamente encampado pelo Estado como divulgador das realizações governamentais e das paisagens turísticas, selando o relacionamento formal entre o poder local e a produção cinematográfica a partir daí. Porém, por mais algumas décadas, a descontinuidade continuaria sendo a tônica dessa atividade no Amazonas.

\section{UM BAIANO DESCOBRE O AMAZONAS}

Quando Luiz Maximino sugeriu a produção de um documentário sob a responsabilidade do Departamento de Turismo e Promoção, o nome do cineasta que assinaria a produção já estava incluído na proposta: "Conversei com Glauber Rocha, o laureado diretor de O Diabo na Terra do Sol (sic) e Barravento, e ele está disposto a dirigir tal documentário", comunicou ele, em missiva ao governador, ao que acrescentou:

Custaria ao Estado 40 milhões [de cruzeiros] e seria distribuído em circuitos comerciais em todo o país. Por intermédio do Itamaraty, por causa do nome do diretor, seria apresentado na Europa e Estados Unidos, inclusive em festivais internacionais de cinema ${ }^{4}$.

A encomenda foi formalizada em contrato assinado entre o Governo do Amazonas e a empresa Luiz Augusto Mendes Produções Cinematográficas, que também havia cuidado da produção de Deus e o Diabo na Terra do Sol. Como produtor, Mendes iria gerenciar os recursos destinados ao trabalho, as requisições de equipamento, mão de obra e outras necessidades de ordem técnica e operacional, bem como acompanhar as etapas de criação e finalização do filme.

O contrato ${ }^{5}$, datado de outubro de 1965 , dispensava o processo de concorrência pública em vista da "especialidade do serviço" e do "reconhecimento da competência e idoneidade" da empresa de Luiz Augusto Mendes, e designava "obrigatoriamente" Glauber como diretor. Além disso, o contrato especificava que o filme deveria ser rodado em cinemascope (ou lente similar) e em cores; já a elaboração do roteiro ficaria a cargo da equipe do Depro com o "consentimento final" de Glauber.

A contar da assinatura do contrato, Glauber passou a ter 60 dias para concluir o filme, que deveria ser entregue até meados de dezembro. De início, houve um atraso no cronograma: embora Luiz Maximino esperasse receber o diretor em Manaus ainda na primeira semana de novembro, a viagem teve de ser postergada ao menos três vezes. A terceira foi motivada por um notório caso de polícia: a prisão de Glauber e outros intelectuais no episódio conhecido como "Oito do Glória", durante um protesto contra a ditadura em frente ao Hotel Glória, no Rio de Janeiro.

Quando desembarcou em Manaus, no dia 14 de dezembro, já livre do problema com a polícia, Glauber foi anunciado como o "mais afamado diretor cinematográfico brasileiro", elogio em muito devido à repercussão que Deus e o Diabo na Terra do So/havia alcançado no exterior ${ }^{6}$. Segundo o Jornal do Commercio, o "astro cinematográfico" vinha "filmar aspectos pitorescos do Amazonas e também do nosso desenvolvimento"7.

Enquanto esteve em Manaus, Glauber concedeu sua única entrevista ao jornalista e crítico José Gaspar, do jornal A Crítica, responsável pela coluna "Cinéfilo". O material ganhou espaço na contracapa da edição do dia 20 de dezembro com o título "Cansaço de valores e conflito moral-ciência". À publicação, ele comentou sobre a produção que estava rodando para o Governo do Amazonas, garantindo que tinha total liberdade de ação para filmar A Conquista do Amazonas, como inicialmente se referia ao documentário: “Nada me foi imposto. Posso, portanto, procurar captar à vontade aquilo que de mais autêntico refletir o estado da região e as promessas que se possam antever para a formação de um novo mundo e uma nova civilização"8.

Presume-se, contudo, que tal liberdade tenha sido apenas relativa, tendo em vista a natureza do trabalho, um filme de propaganda. Além disso, o fato de Glauber estar a serviço do Estado não passou incólume a questionamentos e conjecturas: "muita gente [de Manaus], entendedora do quadro político do momento, estranhou a aceitação de Glauber trabalhar para um governo 'revolucionário'" (LOBO, 1996, p. 122). 
As cartas que Glauber escreveu durante as filmagens de Amazonas, Amazonas, em especial as endereçadas ao produtor Luiz Augusto Mendes, também são documentos reveladores, pois nos permitem assimilar detalhes do processo de autoria do documentário. Nelas, o diretor revela suas intenções, relata os problemas de produção enfrentados e nos põe em contato com uma visão pessoal e repleta de cumplicidade de um autor em relação à sua obra.

Na carta que Glauber remeteu ao produtor em 30 de dezembro de 1965, encontramos uma demonstração do seu envolvimento inicial com o que viria a ser Amazonas, Amazonas, ao mesmo tempo em que percebemos o tom vacilante e inseguro do diretor: "Chego a Manaus e sou recebido com todas as honras. Fui investido aqui de uma responsabilidade maior do que você pode pensar" (ROCHA, 1997, p. 36).

Glauber tomava consciência de que a sua viagem estava cercada de expectativas, principalmente por conta do seu prestígio como cineasta, de quem não se esperava nada menos que uma grande obra. Reservadamente, porém, ele admitia desconhecer a realidade que deveria retratar, o que de certa forma deve ter limitado não só a sua compreensão do contexto amazônico, num curto prazo, como deve ter sido determinante para as escolhas discursivas incorporadas ao documentário.

A seguir, em carta escrita em janeiro de 1966, o cineasta oferece uma visão mais detalhada de como estava concebendo o filme. Nota-se a preocupação em justificar ao produtor mudanças na narrativa do curta, o que acabaria interferindo no conteúdo das imagens e no objetivo original da película: ser uma peça de divulgação dos aspectos turísticos e econômicos do Amazonas.

Quero Ihe esclarecer um detalhe: não houve transformação de documentário turístico em sócio-econômico. Houve um quebra-galho porque aqui não há muito o que filmar de turismo. Aqui chegando havia dois problemas: ou fazer uma série de vistas falsificadas para uma propaganda de turismo ou fazer um documentário com o mínimo de intenção que justificasse a onda da qual o mesmo aqui estava cercado com fofocas no governo e etc. O roteirinho que fiz não é complicado como o Roberto ${ }^{9}$ viu: mostrar um pouco do Amazonas selvagem e lendário e um pouco do Amazonas de hoje. Assim haveria um contraste, despertaria algum interesse (ROCHA, 1997, p. 264, grifo nosso).
A mudança de rumo do documentário, num primeiro momento, só poderia ser justificada pelo desconhecimento de Glauber a respeito dos referidos potenciais turísticos locais ou por uma resistência do diretor e roteirista em seguir à risca as linhas mestras da encomenda. Acreditamos ser possível descartar a primeira hipótese, tendo em vista que o Depro, responsável pela contratação de Glauber, já possuía um planejamento consolidado para o fomento do turismo amazonense, com atenção especial ao turismo de natureza e a roteiros educativos voltados a universitários.

Em relação a Amazonas, Amazonas, a resistência em transformar o filme em mera divulgação turística, como tantos fizeram antes dele, tende a ser um indicativo de certa liberalidade da parte de Glauber, que não gostaria de ver o curtametragem assumir um tom de propaganda estéril, pois o diretor estava mais interessado em fazer um filme com o "mínimo de intenção" e que despertasse "algum interesse". Ainda na carta ao produtor, Glauber ressalta a importância do uso de imagens de interiores e aborda outros detalhes:

Os interiores são importantes por vários motivos: o orgulho da terra aqui é o teatro, no teatro se pode fazer alguma coisa de original. Depois a entrevista com o Governador isenta o documentário de outras falhas inevitáveis e adiantou muito o trabalho, pois fiz transformações de muitas coisas. Agora você veja: sem índio, sem onça, sem cobra, sem vitóriarégia, sem pescaria, sem seringueiro - não é um filme do Amazonas. Muita coisa já foi cortada. Estou vendo o problema dos índios, mas acho indispensável (ROCHA, 1997, p. 264, grifo nosso).

O trecho em destaque deixa entrever que o encontro do cineasta com o governador Arthur Reis permitiu sanar falhas que ele considerava inevitáveis no documentário - ao evocar essas falhas, Glauber provavelmente se remetia à sua assumida ignorância no tema Amazônia/ Amazonas. Isto é, o diretor parece ter encontrado junto ao historiador e intelectual amazonense algumas referências que atuariam como balizadoras do discurso construído por ele em Amazonas, Amazonas.

Glauber encerra esse trecho da carta elencando uma série de elementos que remetem a diferentes representações construídas em torno da região amazônica ao longo do tempo. Da forma como ele expõe, um filme não poderia ser considerado do Amazonas se não incorporasse imagens de índio, 
onça, cobra, vitória-régia, pescaria e seringueiro. Ao mesmo tempo, a ausência dessas imagens no corte final do documentário induz alguns questionamentos: é possível fazer um filme sobre o Amazonas, por exemplo, sem dar espaço aos indígenas? Que contexto sociopolítico legitimaria essa opção?

A carta de janeiro de 1966 ainda é usada por Glauber para pontuar os problemas enfrentados pela equipe durante a produção do documentário, como as chuvas constantes, características do clima amazonense no início do ano, além dos desentendimentos entre ele e o produtor. Pela ênfase contrariada que empregou na carta, é possível perceber que Amazonas, Amazonas significou, em alguma medida, uma experiência malfadada para o cineasta, que passou a considerar o filme "azarado desde as suas origens", sendo motivo para Glauber prometer não fazer outro nem para Luiz Augusto Mendes "nem para ninguém"10.

A recepção a Amazonas, Amazonas foi o que se pode chamar de tímida e, ao contrário do que fora previsto inicialmente, a produtora pouco contribuiu para a distribuição e exibição do filme após a sua conclusão. Em parceria com a Cinemateca do Museu de Arte Moderna, foi o Depro quem realizou a pré-estreia do documentário no dia 11 de abril de 1966, no auditório da Maison de France, no Rio de Janeiro. Promovida pelo Governo do Estado, juntamente com o Grupo de Estudos Cinematográficos (GEC), a estreia em Manaus aconteceu na noite do dia 17 de maio, no Cine Avenida, em avant-premiére para autoridades, intelectuais, artistas e outros convidados. Assim o Jornal A Crítica registrou o lançamento do filme:

A película, em linhas gerais, é um grito ao Brasil, do que se faz, do que se produz e se industrializa no Amazonas, e mostra, por outro lado, o aspecto sócio-econômico que o Estado atualmente experimenta, a luta do homem pela sobrevivência do solo.

Amazonas-Amazonas é o retrato fiel do esforço empreendido no Estado, na produção e na industrialização das nossas riquezas. É um documentário firme daquilo que aqui se faz em matéria de trabalho...11

O valor que o governo desembolsou pelo filme (40 milhões de cruzeiros) chegou a ser alvo de denúncia do deputado estadual Francisco
Guedes de Queiroz, da oposição ao governador Arthur Reis, que articulou a abertura de uma Comissão Parlamentar de Inquérito (CPI) na Assembleia Legislativa, em junho de 1966, para apurar suspeitas de malversação do dinheiro público pelo Governo do Estado. As denúncias, porém, acabaram arquivadas. Em relação ao documentário, chegou-se ao entendimento de que a quantia cobrada estava dentro dos valores de mercado.

O documentário ainda circulou por universidades, teatros e cineclubes de outras capitais, como Rio de Janeiro e Porto Alegre, com destaque para a exibição realizada no cinema particular do Palácio Guanabara, com a presença dos governadores Arthur Reis e Negrão de Lima, e outra no antigo Carré Thorigny, em Paris ${ }^{12}$. Depois dessas exibições iniciais o filme caiu em relativo esquecimento, reaparecendo ocasionalmente em mostras retrospectivas sobre Glauber Rocha.

Posteriormente, o próprio cineasta fez poucas referências à sua experiência no Amazonas. A mais significativa talvez seja a publicada numa edição da revista francesa Positif, em janeiro de 1968. $\mathrm{Na}$ entrevista concedida ao periódico, ele falou ao crítico de cinema Michel Ciment sobre os curtasmetragens que havia produzido até então. Glauber disse não só que "o filme sobre o Amazonas é um fracasso total; foi minha primeira tentativa em

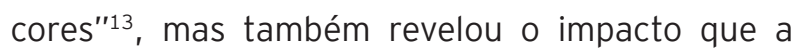
experiência teve no seu imaginário sobre a região: "Cheguei ao Amazonas com uma ideia preconcebida e descobri que não existia a Amazônia lendária e mágica, a Amazônia dos crocodilos, dos tigres, dos índios etc." (ROCHA, 2004, p. 110).

Numa análise comparativa, as palavras de Glauber têm similaridade com as "impressões gerais" que Euclides da Cunha escreveu no início do século $X X$, quando de sua passagem pela região como integrante da Comissão Mista Brasileiro-Peruana de Reconhecimento do Alto Purus, entre 1904 e 1905. O autor do clássico Os Sertões registrou que

ao revés da admiração ou do entusiasmo, o que sobressalteia geralmente, diante do Amazonas, [...] é antes um desapontamento. A massa de águas é, certo, sem par, capaz daquele terror a que se refere Wallace; mas como todos nós desde mui cedo gizamos um Amazonas ideal, mercê das páginas singularmente líricas dos não sei quantos viajantes que desde Humboldt até hoje contemplaram a Hylae prodigiosa, com um espanto quase 
religioso - sucede um caso vulgar de psicologia: ao defrontarmos o Amazonas real, vemo-lo inferior à imagem subjetiva há longo tempo prefigurada (CUNHA, 2011, p. 17).

No caso de Glauber, é curiosa a ausência da menção ao "fracasso" na versão da entrevista à Positif que foi publicada no livro Revolução do Cinema Novo, pouco antes da morte do cineasta: "O filme sobre o Amazonas é meu primeiro ensaio em cores" (ROCHA, 2004, p. 110), diz a tradução, simplesmente. Nessa coletânea de textos autorais e entrevistas, que dão ao livro um caráter autobiográfico e de acerto de contas com o Cinema Novo, Glauber de fato suprimiu certos trechos que "outrora atendiam a objetivos agora superados pelo tempo", como esclareceu Carlos Augusto Calil, coordenador da primeira edição da obra. Enquanto revisava os textos a serem publicados, o cineasta teria se arrependido da declaração pouco elogiosa a Amazonas, Amazonas?

\section{AMAZONAS, AMAZONAS EM SEQUÊNCIAS}

Seguindo um critério narrativo-temporal, analisamos Amazonas, Amazonas a partir da sua divisão em seis grandes sequências/blocos, que nominamos da seguinte forma: "Conquista da 'clássica Amazônia"' (Bloco I), "O homem e o meio" (Bloco II), "Fausto e cidade em crise" (Bloco III), "Integração e (sub) desenvolvimento" (Bloco IV), "Gente em crise" (Bloco V) e "Exaltação do 'Amazonas real"' (Bloco VI).

Em sua sequência de abertura (Bloco I), o filme mostra imagens aéreas sobre uma área de mata fechada e sobre o Encontro das Águas, um dos emblemas turísticos e naturais da cidade de Manaus. Amazonas, Amazonas recorre com frequência a esse tipo de movimento de câmera (travellings, panorâmicas e planos abertos), sugerindo uma varredura da paisagem com o intuito de melhor ambientar o espectador. Esse recurso se tornou uma espécie de lugar-comum em filmes sobre a região pelo menos desde No Rastro do Eldorado (1925), de Silvino Santos. Além da ideia de revelar o gigantismo natural da Amazônia, por trás desse código visual está a sugestão de uma paisagem primeva e homogênea, como um tapete verde ainda intocado pelo homem, mas que esconde riquezas e fauna exótica por baixo do manto florestal.

Junto a essas imagens de uma Amazônia figurativamente originária, tem início a narração propriamente dita, que nesse primeiro momento adota a posição de uma voz performática em primeira pessoa, logo identificada como sendo a do navegador espanhol Francisco de Orellana, a quem se atribui o descobrimento das terras ao longo do rio Amazonas, em 1542.

Transcorrida essa primeira parte, que dura cinco planos, a voz de Amazonas, Amazonas muda de posição discursiva: passa do narradorpersonagem ao narrador-onisciente, também chamado de "voz de Deus". Segundo Vanoye e Goliot-Lété (2012), essa é a voz do saber e do poder no cinema, pois imprime um efeito de objetividade e cientificidade ao que está sendo dito. É nesse tom que o narrador começa a abordar criticamente a "clássica Amazônia" como uma noção pertencente ao passado, quando ainda se interpretava a região por meio de dicotomias como inferno e paraíso. Com isso, o filme se distancia da visão apresentada anteriormente ao reforçar que o mundo exótico criado pelos primeiros viajantes não passa de produto de uma imaginação que se exaltou diante das terras descobertas.

A desconstrução do imaginário calcado no exótico e amplificado pelos relatos dos primeiros viajantes e cientistas que passaram pela Amazônia também era um esforço empreendido pela intelectualidade amazonense há algum tempo, em especial após a derrocada da economia da borracha, momento em que se tentou dar vazão a uma nova discursividade para chamar a atenção para os problemas socioeconômicos locais. Como pontuou Arthur Reis em uma de suas obras, a região deveria, enfim, começar a ser encarada mais realisticamente (REIS, 1972).

O Bloco II começa a delimitar um distanciamento crítico em relação à abertura do bloco anterior, agora identificado como um discurso superado, pertencente ao colonizador. Nesta sequência, a voz do narrador se situa claramente no tempo presente como autora de comentários que levam em consideração o contexto em que o filme foi produzido, isto é, os anos 1960: “O Amazonas que conhecemos é outro. O Amazonas de hoje, maior Estado do Brasil (...)", diz a locução.

Essa temporalidade também passa a se refletir no conjunto de imagens, que mostra signos próprios da sociedade amazônica contemporânea, além de evidenciar pela primeira vez o elemento humano, 
representado por duas pessoas conduzindo uma canoa. Porém, a câmera não se preocupa em captar essas figuras em sua individualidade; em vez disso, elas são registradas em plano aberto, apequenadas pela grandiosidade da paisagem, cumprindo a função de modelos do habitante da região.

Trata-se da representação do homem amazônico que, embora já tenha fixado raízes na região, ainda luta para "desenvolver a sua civilização" e "busca uma cultura a partir das condições especiais do meio", como pontua o narrador. Há, portanto, a sugestão de que a cultura/civilização local se configura como um processo inconcluso, ainda por se fazer. Com isso, o filme apresenta a luta do homem para domar a natureza, em seu esforço para fazer uma cultura/civilização emergir de um meio hostil, como a síntese histórica da sociedade amazônica. Esse processo de constante adaptação é representado no filme como algo tão penoso no tempo presente quanto na época do descobrimento.

É essa visão que vai ensejar, segundo Francisco de Oliveira (2009), o projeto de "reconquista" da Amazônia a partir da política de integração idealizada durante a ditadura militar, pois naquele momento os inimigos e os desafios eram outros: a cobiça internacional e o subdesenvolvimento. Cabia ao regime intervir nas terras ocupadas por uma "não-gente, incapaz de cuidar de si própria" e que oferecia perigo por sua vulnerabilidade, "pela sua incapacidade cultural - segundo os critérios dos brancos - de cuidar de vastas riquezas" (OLIVEIRA, 2009, p. 87).

Ainda neste bloco, temos outro conjunto de planos que é bastante significativo por conter a única entrevista utilizada em Amazonas, Amazonas. Em plano aberto, vemos o diretor Glauber Rocha de perfil e pernas cruzadas sobre um tronco de árvore. Ele estende um microfone na direção de um homem sentado bem à sua frente, mas é a paisagem que ocupa a maior parte do quadro.

Como Fernanda Bizarria (2008) já havia sugerido em análise anterior, o filme elege o entrevistado como representante típico do trabalhador da Amazônia, tanto que seu nome não é identificado, nem seu rosto pode ser distinguido na imagem. Esse artifício fica mais evidente quando a voz dele, em off, é sobreposta à imagem de outros trabalhadores, como se todos compartilhassem de uma história comum.
Durante a entrevista, passamos a conhecer a história do personagem, um trabalhador rural migrante que se mudou para o Amazonas em busca de melhores condições de vida. Para ele, contudo, a esperança de prosperidade estava ligada à posse da terra, problema que a ditadura militar agravou ao consagrar a ideia de que latifúndios produtivos deveriam ser estimulados, a despeito da sua desigual distribuição. Segundo Carlos Gonçalves (2001), os conflitos de terra ganharam contornos dramáticos sobretudo ao longo dos eixos rodoviários da região, levando os militares a assumirem o controle direto dos órgãos relacionados à questão fundiária.

A certa altura, a entrevista é interrompida por uma intervenção brusca do diretor, demonstrando a relação desigual e autoritária estabelecida entre o cineasta e o entrevistado. A interrupção efusiva revela quem de fato está no controle da narrativa, mas essa interrupção também pode ser interpretada de maneira menos maniqueísta e até irônica, como uma crítica escamoteada por Glauber. Quando grita "Corta!" (em off), ele delimita até onde o filme consegue dar espaço à voz do cidadão insatisfeito, sem que isso sugerisse ideias consideradas subversivas, como a reivindicação por uma reforma agrária.

Sob esse ponto de vista, o aprofundamento no tema teria sido inviabilizado, em primeira instância, não pelo cineasta Glauber Rocha, que era simpático à causa e chegou a abordar a questão em seu longa-metragem Deus e o Diabo na Terra do Sol, mas por uma conjuntura política que elegeu como inimigo interno, por exemplo, o movimento das Ligas Camponesas no Nordeste.

No Bloco III, temos o retorno da voz do narrador, que mais uma vez assume um tom performático em primeira pessoa. Desta vez, elege-se o seringueiro como o personagem para dramatizar a saga dos retirantes nordestinos que vieram para a Amazônia durante o Ciclo da Borracha, tema central deste bloco narrativo.

Nos planos seguintes, o filme aborda a agonia da economia gomífera, provocada pelo início da produção de borracha nas colônias inglesas na Ásia, o que abriu uma concorrência acirrada com o produto amazônico. "Queda dos preços, do consumo, consequente queda da exploração, queda dos reinos, desespero das ambições, 
orgulho ofendido, falências", informa o narrador. É o discurso da cidade em crise, que predominou na capital amazonense entre 1920 e 1967, de acordo com José Aldemir de Oliveira (2003). No documentário de Glauber, essa ideia aparece representada na herança arquitetônica da Belle Époque que ainda compunha a paisagem urbana de Manaus em 1965: prédios e palacetes em estado de abandono, deterioração e calamidade.

A única construção destoante nesse conjunto de imagens ligadas à crise da cidade é o Palácio da Justiça, que surge na película como signo ilustrativo do Estado quando o narrador diz que "a falta de planejamento encerrava mais um ciclo econômico do Brasil passado". Na perspectiva da análise, esse discurso sugere a intenção de comparar a inoperância de um "Brasil passado" com a racionalidade eficiente do novo Brasil, que, afinal, estava engendrando Amazonas, Amazonas.

Esse contraste é mais bem desenvolvido no Bloco IV, que volta a abordar o tempo em que o filme foi produzido. Aqui, a intenção não é mais realçar apenas os elementos arquitetônicos (essencialmente ligados ao passado) que reforcem o discurso da cidade em crise, mas atualizar o espectador em relação ao estado atual da cidade de Manaus, que passa a sintetizar a situação de todo o Amazonas.

Se a memória do "já teve" foi o que restou do fausto de outrora ("Manaus da memória da borracha"), a cidade que o filme procura mostrar a partir de agora "ressurgiu mais lenta e realista [...] à espera que o Amazonas seja incorporado ao Brasil, não como uma peça acessória, mas como agente do nosso processo econômico" (AMAZONAS, AMAZONAS, 1966). Como Oliveira (2003) pontua, a atitude passiva de esperar pela ajuda nacional passou a ser um traço marcante da elite local desde a crise da borracha, e é nesse compasso que a História, na região, se tornou algo sempre por se fazer.

Neste sentido, o espaço-tempo da cidade para esse segmento é sempre inacabado, é o nunca chegar ao ponto final. Aqui se está sempre à espera das migalhas que nos são postas pelos de fora. Isso decorre de o espaço-tempo local se caracterizar pelo atraso, um processo que não se conclui, ações que não chegam ao fim (OLIVEIRA, 2003, p. 163).

Já o discurso segundo o qual o Amazonas, e a Amazônia como um todo, precisavam ser incorporados ao processo econômico brasileiro pode ser interpretado à luz da produção de Arthur Reis, um dos principais influenciadores do debate sobre essa questão no período. O historiador defendia o reconhecimento da Amazônia como engrenagem estruturante ("não como uma peça acessória", de acordo com o filme) do desenvolvimento do País e da sua consolidação como potência mundial. Não se tratava mais de uma integração meramente territorial, ainda que necessária, mas de fomentar um projeto desenvolvimentista que incluísse efetivamente a Amazônia em seu horizonte imediato.

Esse diagnóstico converge com a análise que Lobo (1994) fez de Amazonas, Amazonas no livro A tônica da descontinuidade. Para ele, o filme de Glauber, realizado com dinheiro público, tinha um discurso puramente oficialista e fazia,

pelo menos no plano da narração, o discurso ideológico da elite local que se achava abandonada "pelo Brasil" em termos de ajudas e financiamentos. [...] É o discurso da decadência em que vive a região naquele momento pré-Sudam, pré-Zona Franca, pré-Transamazônica, pré-Funai, pré-Projeto Rondon (LOBO, 1994, p. 132).

Na última parte desta sequência do filme, o narrador expõe mais uma vez um contraste de temporalidades, recurso dialético comumente usado ao longo de todo o documentário. Fazendo referência à sua intervenção anterior, na qual abordou os potenciais econômicos do Estado, ele diz:

Mas enquanto se pensa no futuro, a realidade do presente faz pensar no mais remoto passado. Um estilo de trabalho que, no dizer do professor Arthur Reis, faz da Amazônia a região mais subdesenvolvida do País (AMAZONAS, AMAZONAS, 1966).

É curiosa a menção explícita do narrador a Arthur Reis, que, munido do capital simbólico de professor, confere autoridade ao que está sendo dito e mostrado. Como Bourdieu (1989) ressalta, ao tratar do capital político como um crédito baseado na crença e no reconhecimento fora desse campo ${ }^{14}$, "basta que as ideias sejam professadas por responsáveis políticos para se tornarem em ideias-forças capazes de se imporem à crença ou mesmo em palavras de ordem capazes de mobilizar ou desmobilizar" (BOURDIEU, 1989, p. 187). É na citação direta ao então governador que o filme, procurando imprimir cientificidade à locução, descortina a relação de poder implícita ao seu discurso - que já não é mais apenas seu, mas também de Arthur Reis. 
No Bloco $V$, que é uma sequência de transição, sugerindo um encaminhamento para o desfecho do documentário, a voz do narrador adquire um novo grau de performatividade ao falar na primeira pessoa do plural, como quem engloba o espectador no percurso feito até aqui através da História e da problemática amazonense: narrador e público fizeram lado a lado a mesma viagem.

A narração, porém, evidencia a posição (ou posições) da qual o discurso é enunciado, personificando em uma única sentença uma multiplicidade de vozes sociais. Assim, é o conquistador quem fala o quanto foi difícil vencer índios na ocupação do território; é o estadista colonial quem conta sobre como fez o colono português se cruzar com o índio, forjando a "nova raça"; e é o burocrata moderno, imbuído da missão de sanear a Amazônia, quem comenta sobre a luta contra mazelas como o impaludismo e a verminose. Em resumo, o narrador é uma figura de poder, que em diversas épocas empreendeu uma conquista diferente na região. Mas, no trecho seguinte, a voz volta a se revestir de impessoalidade:

Parintins, Itacoatiara, Manacapuru, Cacau-Pirera, estranhos nomes que abrigam gentes prisioneiras dos grandes distantes desconhecidos. Dos grandes distantes demais para apenas 800 mil pessoas que ainda vivem da mais rude agricultura, da pesca, do diluído artesanato indígena, apenas de uma vontade inconsciente de sobreviver. População que necessita de condições humanas de cultura, moradia, saúde (AMAZONAS, AMAZONAS, 1966).

Esse é o retrato não mais de uma cidade, mas de um povo em crise, cuja representação se dá por meio de uma hipérbole: a população amazonense, especialmente a do interior, achava-se prisioneira na própria terra, vivendo precariamente. Nesse estágio de subdesenvolvimento, nem a rude agricultura e a pesca, nem o diluído trabalho artesanal, seriam capazes de levar essa gente a uma saída.

De acordo com esse discurso, o amazonense é antes de tudo um sobrevivente, desassistido em suas necessidades básicas de saúde, moradia e cultura - este último elemento surge no filme a partir de uma concepção conservadora, que ignora as dinâmicas internas de produção simbólica em uma sociedade, apesar de todas as carências estruturais que possam definir seu modo de vida.

Dessa forma, a quinta sequência está conceitualmente ligada aos Blocos III e IV do filme, no sentido de que todos esses trechos servem de alerta para o subdesenvolvimento local e para a falta de amparo por parte do governo central, seja pela ausência de planejamento ou pelo desinteresse das autoridades em interceder pela região. Com isso, Amazonas, Amazonas se insere numa linha de produções realizadas entre as décadas de 50 e 60 que, longe de serem efetivamente populares, como desejavam seus diretores, acabavam estabelecendo uma via de comunicação com os dirigentes do País, conforme escreveu o crítico Jean-Claude Bernardet:

\begin{abstract}
Aparentemente, são filmes feitos para o povo, mostrando-lhe sua situação e incitando-o à reação. [...] Se os filmes não conseguiram esse diálogo é porque não apresentavam realmente o povo e seus problemas, mas antes encarnações da situação social, das dificuldades e hesitações da pequena burguesia, e também porque os filmes se dirigiam, de fato, aos dirigentes do país. É com estes últimos que os filmes pretendiam dialogar, sendo o povo assunto do diálogo. É aos dirigentes que se apontam as favelas e as condições subhumanas de vida (BERNARDET, 1978, p. 51-52).
\end{abstract}

Por último, as menções feitas ao indígena nesta sequência merecem um olhar mais crítico. Em Amazonas, Amazonas, o índio é retratado como a-histórico, o elemento vencido no processo de conquista e dominação da região. A cultura dos povos tradicionais tampouco encontra espaço no documentário, a não ser pela herança linguística identificável nos "estranhos nomes" que batizam cidades como Itacoatiara e Parintins e por um "artesanato diluído". E, assim como o artesanato, o índio também se acha diluído no povo amazonense: quando este é mostrado ou citado, é sempre sob o viés da miscigenação, da "nova raça" forjada pelo colonizador.

Apesar da disposição inicial do diretor em incorporar o indígena ao documentário, afinal, "sem índio [...] não é um filme do Amazonas" (ROCHA, 1997, p. 264), a representação desfavorável que o curtametragem acaba fazendo dessa população estava em sintonia com a historiografia tradicional amazônica, elaborada sempre sob a perspectiva do vencedor, nunca do vencido. Conforme Hélio Dantas (2014) explica, ao atribuir um papel civilizador, heroico, disciplinador e nacionalista ao elemento português, o próprio Arthur Reis ajudou a escrever uma História do Amazonas do ponto de vista do conquistador cristão ocidental, que ele considerava a verdadeira matriz fundadora da civilização 
tropical. Nesse processo, indígenas, caboclos e negros se tornaram residuais, coadjuvantes e instrumentais, pois a influência cultural maior foi de origem lusitana.

A sequência final (Bloco VI) retoma o tom épico do início, agora num registro enunciativo mais sentimental, fazendo uma espécie de exaltação de um Amazonas que tenta se reerguer acima das adversidades elencadas e mostradas anteriormente. Para exaltar as múltiplas potencialidades do Amazonas, descortinando perspectivas de um futuro mais próspero que o passado e o presente, o documentário conclui seu discurso com um vaticínio: "[...] de tudo isto, Amazonas, te fazes canto e símbolo de um novo mundo". Com isso, Glauber tenta sintetizar o que entendia ser o devir histórico do estado e da região, reforçando o seu interesse constante pelo novo.

\section{O FILME SOB PERSPECTIVA}

A partir do que foi exposto, Amazonas, Amazonas suscita algumas problematizações quanto às representações que faz da realidade amazônica e dos seus componentes sociais. Em primeiro lugar, identificamos que o filme recorre ao anonimato como principal ferramenta de generalização das situações retratadas, de modo que os comentários do narrador onisciente se apliquem à totalidade da sociedade local. Assim é que, nem o personagem entrevistado no Bloco II é nomeado, nem as feições da maioria das pessoas que aparece na tela são identificáveis. Já a discussão em torno da questão agrária, se não é completamente ocultada no documentário, tem a sua potencialidade crítica silenciada e reduzida quando o diretor interrompe a entrevista com o trabalhador rural.

Embora o documentário de Glauber procura representar o povo, a este não cabe o poder final da enunciação no filme. Quando ele se pronuncia, é apenas para ilustrar um argumento que já chega pronto até nós. Essa é, aliás, uma limitação linguística do modelo sociológico de filmes documentais, de acordo com Bernardet (2003). Mesmo que o interesse social estivesse embutido nesse tipo de filme, ele não necessariamente conseguia abrir espaço para a plena emergência do outro, ainda que este tivesse a oportunidade de se manifestar por meio de entrevistas como a que vimos em Amazonas, Amazonas.
Aqui, chegamos a uma questão central que permeia toda a análise: se sabemos a quem o discurso de Amazonas, Amazonas se dirige, resta-nos inferir sobre a sua origem. Nesse processo, não só o caráter interdiscursivo da obra ganha relevância, mas também as relações de poder e micropoder nas quais o documentário esteve envolvido. Tomemos como exemplo o silêncio do filme acerca da presença do indígena na sociedade regional.

Apesar do interesse inicialmente manifestado por Glauber, o filme não se atém a essa questão e nem se preocupa em registrar a imagem desse grupo social. De certa forma, pode ter havido um direcionamento por parte do governo ou do Depro para que o cineasta não privilegiasse essa temática, possivelmente para que a obra se distanciasse do perfil etnográfico que havia marcado filmes anteriores produzidos na região. Afinal, a ideia que se tinha do indígena naquele momento era completamente integracionista, isto é, o nativo precisava ser assimilado pela sociedade e pelo mundo do trabalho. Como observado na análise do Bloco V, essa visão etnocêntrica estava presente sobretudo na historiografia clássica e no pensamento social em circulação na Amazônia nos anos 60, embora ela ainda tenha bastante lastro nos dias de hoje.

Ao mesmo tempo, vale destacar que Glauber chegou ao Amazonas alheio à realidade local e cheio de ideias pré-concebidas, como ele mesmo revelou, e por isso a sua capacidade de assimilar as complexidades de um novo contexto em tão pouco tempo pode ter se tornado permeável às pressões externas. Certo é que Amazonas, Amazonas não se aventura em inovações argumentativas; ao contrário, seu discurso está histórica e sociologicamente referenciado, basta lembrarmos da citação direta a Arthur Reis no Bloco IV.

Esse processo de entrecruzamento discursivo pode ser compreendido por meio do conceito de dialogismo (BAKHTIN, 2014), desenvolvido pelo filósofo da linguagem Mikhail Bakhtin. Da ideia de dialogismo provém a noção de que os sentidos não são puros ou indivisíveis, pois carregam sempre a perspectiva de outras vozes sociais. Segundo essa concepção, a relação dialógica é o princípio constitutivo da linguagem e a condição do sentido do discurso (BARROS, 2003).

De acordo com Bakhtin, nossa fala no cotidiano contém palavras de outrem em abundância, o 
que também faz do dialogismo uma relação de alteridade, pois se caracteriza como o diálogo com o discurso e as palavras de outros, isto é, com os discursos alheios sobre o mesmo objeto. O dialogismo implica, ainda, um processo de elaboração da memória discursiva, como explica Orlandi (2009). Segundo ela, seria uma ilusão acharmos que somos a origem do que dizemos, uma vez que estamos sempre retomando sentidos acionados anteriormente.

Essa ancoragem discursiva/dialógica, que se encontra diluída ao longo de Amazonas, Amazonas, pressupõe a existência de um corpus de conhecimentos prévio, fora do qual o documentário não estaria legitimado. Essa percepção nos remete, de igual modo, àquilo que Foucault (2009) genericamente chama de "sistemas de sujeição do discurso", que impõem limites à prática discursiva por meio de regras de funcionamento, interdição, separação e rejeição, pondo em xeque a ideia de autonomia do enunciado.

Suponho que em toda sociedade a produção do discurso é ao mesmo tempo controlada, selecionada, organizada e redistribuída por certo número de procedimentos que têm por função conjurar seus poderes e perigos, dominar seu acontecimento aleatório, esquivar sua pesada e temível materialidade (FOUCAULT, 2009, p. 8-9).

Diante disso, é possível que a entrevista que Glauber relatou ter feito com o governador Arthur Reis, embora não utilizada no corte final do filme, foi uma forma encontrada (pelo governo?) para mediar o "acontecimento aleatório" do documentário, mitigando seus potenciais perigos.

Nos autos da CPI que investigou, dentre outras coisas, o valor pago ao cineasta pelo filme, o diretor do Depro, nos esclarecimentos prestados à comissão, também deu indicativos sobre a base conceitual que o cineasta teria usado como ponto de partida para a produção:

O documentário Amazonas... Amazonas é a primeira obra séria de divulgação cinematográfica feita na região Amazônica. Nela o Amazonas se apresenta estudado sociologicamente e o autor, Glauber Rocha, leu, durante um mês, as principais obras escritas sobre o nosso Estado e foi obrigado a reescrever, por várias vezes, seu roteiro (grifo nosso) ${ }^{15}$.

As "principais obras escritas" sobre o Amazonas, portanto, surgem na fala de Luiz Maximino munidas de uma função reguladora sobre o que "podia e devia ser dito" (ORLANDI, 2009) no filme.
Levando em conta que, por seu caráter expositivo/argumentativo, a obra busca predispor a opinião pública a aceitar as soluções oficiais para os problemas apresentados, também não se pode negligenciar o peso simbólico do aparato governamental que possibilitou a produção de Amazonas, Amazonas. Para Nichols (2008), a existência de uma estrutura institucional por trás de um documentário acaba impondo uma maneira também institucional de ver e falar. Em outras palavras, tanto o cineasta quanto o público estão cercados por um conjunto de limites e convenções.

Quando entramos em uma estrutura institucional que patrocina essas maneiras de falar, assumimos um poder instrumental: o que dizemos e decidimos pode afetar o curso dos acontecimentos e acarretar consequências. Essas são maneiras de ver e falar que são também maneiras de fazer e atuar. 0 poder atravessa-as. [...] Eles são veículos de ação e intervenção, poder e conhecimento, desejo e vontade (NICHOLS, 2008, p. 68-69).

Assim é que o documentário de Glauber sela um compromisso com uma visão então hegemônica acerca da problemática amazônica. O filme apresenta determinada leitura sobre a "verdade" e a "realidade" da região, assumindo um caráter "positivo" em relação às perspectivas para o futuro, atrelado ao desenvolvimentismo e à ação estatal, numa clara contraposição aos discursos fatalistas de outrora. Apegado a uma lógica essencialmente expositiva, que é o modo ideal para transmitir informações ou mobilizar apoio dentro de uma estrutura preexistente ao filme, Amazonas, Amazonas "aumenta nossa reserva de conhecimento, mas não desafia ou subverte as categorias que organizam esse conhecimento" (NICHOLS, 2008, p. 144).

Nisto reside a maior ambiguidade do filme: em essência, Glauber não conseguiu ir além (por não poder ou não saber) do que pregava o discurso oficial. A obra assume o discurso da elite intelectual e política da época, em detrimento de uma perspectiva mais crítica e emancipadora.

\section{CONSIDERAÇÕES FINAIS}

Crítico dentro de limites impostos de modo mais ou menos explícito pela estrutura institucional que o financiou, Amazonas, Amazonas faz um discurso sobre a Amazônia que se associa à ideia de modernização conservadora e centralizadora adotada pelo regime militar, pois não se tratava de 
desenvolver a região a partir de seus padrões de vida e cultura, mas de integrá-la economicamente ao corpo da nação, o que sugere um processo a ser realizado de cima para baixo. Retomando Foucault (2009), diríamos que é a essa formação discursiva dominante que o filme se filia e a partir da qual ele se expressa.

Desse modo, vemos na tela uma representação de Amazônia enquanto espaço propício ao desenvolvimento, aberto à expansão capitalista a ser incentivada pelo Estado, com destaque para o potencial de exploração das riquezas do solo. Por outro lado, o filme busca ressaltar o que considera ser o drama contemporâneo da população local em sua tarefa de "sobreviver" apesar do isolamento e das adversidades impostas pelo meio. Ao operar um apagamento de possíveis conflitos estruturantes, como a questão da terra, Amazonas, Amazonas mantém seu foco na representação da carência da região, o que por si só justificaria os projetos de integração.

Expositivo sem ser excessivamente didático, o documentário foge às referências elogiosas a autoridades ou ao regime e evita obviedades como a apresentação de programas e ações de governo, e por isso ele parece abordar apenas vagamente as perspectivas e soluções para os problemas citados. 0 próprio projeto inicial da Zona Franca de Manaus, que a partir de 1967 se estruturaria como centro industrial, comercial e agropecuário, é ignorado. A "exaltação" dos minutos finais assume, então, um tom mais épico/literário do que propriamente político, embora esteja implícita a sua finalidade.

É preciso destacar, ainda, as relações de poder que permeiam o filme de Glauber. Levando em consideração as suas condições sociais de produção, o documentário faz o discurso possível sobre a Amazônia naquela conjuntura. Com isso, não pretendemos relativizá-lo, mas compreendêlo à luz das diferentes forças que o cercam.

Entendemos, por exemplo, que Amazonas, Amazonas é fruto de uma relação estratégica entre prestígio e conveniência. Se o governo buscava chamar a atenção para os problemas e as potencialidades regionais, e por isso contratou um diretor que, por seu reconhecimento, poderia transferir visibilidade e capital simbólico ao próprio governo e à sua causa, Glauber encarou a encomenda como uma forma de viabilizar a realização do seu próximo filme, Terra em Transe, e aliviar sua condição financeira (ROCHA, 1982; VENTURA, 2000).

A conveniência política também estava em jogo, pois o diretor havia acabado de se livrar de um embate com a ditadura, embora não estejamos inclinados a endossar a tese de cooptação que a contratação do cineasta poderia sugerir. Sem dúvida, o filme não expressa necessariamente a visão e os ideais de Glauber, mas podemos encontrar nele algumas características do seu pensamento de país, como o sentimento nacionalista e o interesse pela ideia do "novo" enquanto categoria social, artística e política.

Mesmo que se trate de uma encomenda governamental, o documentário não deve ser posto ao lado de outras produções que fazem propaganda institucional mais explícita, ao modo de verdadeiros panfletos, mas tampouco ele se aproxima da inventividade de outros trabalhos documentais do diretor, como DiCavalcanti(1977). Amazonas, Amazonas tem a sua peculiaridade: é como se Glauber, consciente da posição em que se encontrava, subitamente tendo que agenciar suas obrigações e seus desejos entre os campos político e artístico, tivesse buscado produzir algo nesse meio termo.

O filme desperta interesse, sobretudo, por seu viés histórico e sociológico, como registro de uma visão sobre a Amazônia que, em alguns aspectos, perdura na atualidade, especialmente no discurso de parcela da classe política. A diferença é que, hoje, os pensamentos divergentes também ganham visibilidade dentro desse campo, ampliando a pluralidade de vozes e discursos disponíveis na sociedade. Mesmo sob ataque, movimentos como o indígena e o ambientalista oferecem ao debate público novas maneiras de encarar a problemática amazônica, num apelo ao respeito à diversidade cultural, à sustentabilidade e às diferentes formas de ser e estar na região.

\section{NOTAS}

1. Disponível em: https://youtu.be/tN48q7yLWnA.

2. CORRÊA, Luiz Maximino de Miranda. [Carta] 08 set. 1965, Rio de Janeiro [para] REIS, Arthur Cézar 
Ferreira, Manaus. Acervo da Biblioteca Arthur Reis, Secretaria de Cultura do Amazonas, Manaus.

3. CORRÊA, Luiz Maximino de Miranda. [Carta] 02 nov. 1965, Rio de Janeiro [para] REIS, Arthur Cézar Ferreira, Manaus. Acervo da Biblioteca Arthur Reis, Secretaria de Cultura do Amazonas, Manaus.

4. CORRÊA, Luiz Maximino de Miranda. [Carta] 08 set. 1965, Rio de Janeiro [para] REIS, Arthur Cézar Ferreira, Manaus. Acervo da Biblioteca Arthur Reis, Secretaria de Cultura do Amazonas, Manaus.

5. ESTADO DO AMAZONAS. Diário Oficial. Termo de contrato de locação de serviços. Manaus, 28 de outubro de 1965, p 6-7.

6. A CRÍTICA. "Glauber Rocha em Manaus". Manaus, 15 de dezembro de 1965, p. 1.

7. JORNAL DO COMMERCIO. "Astro cinematográfico vem a Manaus". Manaus, 2 nov. 1965.

8. A CRÍTICA. "Cansaço de valores e conflito moral-ciência". Manaus, 20 dez. 1965, p. 8.

9. Glauber estava se referindo, provavelmente, ao diretor de produção e montador do filme, o baiano Roberto Pires.

10. Logo em seguida, contudo, Glauber foi para - Maranhão, onde foi incumbido de registrar a posse do governador recém-eleito, José Sarney. 0 trabalho resultou no curta-metragem Maranhão 66, mais conhecido e citado que Amazonas, Amazonas.

11. A CRÍTICA. "Amazonas Amazonas hoje em avantpremiére no Avenida". Manaus, 17 mai. 1966, p. 1.

12. DEPRO. Relatório de atividades. Manaus, 28 jan. 1967. Acervo da Biblioteca Arthur Reis, Secretaria de Cultura do Amazonas, Manaus.

13. POSITIF 91. "Entretien avec Glauber Rocha". Paris, janeiro de 1968, p. 20.

14. No caso de Arthur Reis, o capital político de que ele dispunha era fruto da reconversão de um capital de notoriedade e de qualificações específicas granjeados lenta e continuamente em outros domínios, como nos campos cultural e científico (BOURDIEU, 1989).

15. ASSEMBLEIA LEGISLATIVA DO AMAZONAS. Relatório da Comissão Parlamentar de Inquérito: anexos sobre o Departamento de Turismo e Promoção. Manaus, 1966.

\section{REFERÊNCIAS BIBLIOGRÁFICAS}

BAKHTIN, Mikhail. Questões de literatura e de estética: a teoria do romance. $7^{\text {a }}$ ed. São Paulo: Hucitec, 2014.

BARROS, Diana Luz Pessoa de. Dialogismo, polifonia e enunciação. In: BARROS, Diana Luz Pessoa de; FIORIN, José Luiz (org.). Dialogismo, polifonia e intertextualidade. São Paulo: Edusp, 2003, pp. 1-9.

BARROS, José D'Assunção. Cinema e história: entre expressões e representações. In: NÓVOA, Jorge; BARROS, José D'Assunção (Orgs.). Cinemahistória: teoria e representações sociais no cinema. $3^{a}$ ed. Rio de Janeiro: Apicuri, 2012, p. 55-105.

BATISTA, Djalma. o complexo da Amazônia: análise do processo de desenvolvimento. Manaus: valer, 2007.

BERNARDET, Jean-Claude. Brasil em tempo de cinema. $3^{\text {a }}$ ed. Rio de Janeiro: Paz \& Terra, 1978.

BERNARDET, Jean-Claude. Cineastas e imagens do povo. São Paulo: Companhia das Letras, 2003.

BIZARRIA, Fernanda. A construção dasidentidades no documentário: os povos amazônicos no cinema. Manaus: Edições Muiraquitã, 2008.

BOURDIEU, Pierre. 0 poder simbólico. Lisboa: Difel, 1989.

BOURDIEU, Pierre. Razões práticas: sobre a teoria da ação. 9a ed. Campinas: Papirus, 1996.

COSTA, Selda Vale da. Eldorado das Ilusões. Cinema \& Sociedade: Manaus (1897/1935). Manaus: Editora da Universidade do Amazonas, 1996.

CUNHA, Euclides da. Amazônia: um paraíso perdido. Org.: Tenório Telles. $2^{\mathrm{a}}$ ed. Manaus: Valer, 2011.

DANTAS, Hélio. Arthur Cézar Ferreira Reis: trajetória intelectual e escrita da história. Jundiaí: Paco Editorial, 2014.

FOUCAULT, Michel. A ordem do discurso. $19^{\mathrm{a}} \mathrm{ed}$. São Paulo: Edições Loyola, 2009.

GOMES, João Carlos Teixeira. Glauber Rocha, esse vulcão. Rio de Janeiro: Nova Fronteira, 1997.

GONÇALVES, Carlos Walter Porto. Amazônia, Amazônias. São Paulo: Contexto, 2001. 
LOBO, Narciso J. Freire. A tônica da descontinuidade: cinema e política em Manaus nos anos 60. Manaus: Editora da Universidade do Amazonas, 1994.

NICHOLS, Bill. Introdução ao documentário. $3^{\text {a }}$ ed. Campinas: Papirus, 2008.

NóVOA, Jorge. Apologia da relação cinemahistória. In: NÓVOA, Jorge; BARROS, José D'Assunção (Org.). Cinema-história: teoria e representações sociais no cinema. $3^{a}$ ed. Rio de Janeiro: Apicuri, 2012, p. 19-54.

OLIVEIRA, Francisco de. In: D'INCAO, Maria Angela; SILVEIRA, Isolda Maciel da (Org.). A Amazônia e a crise da modernização. $2^{a}$ ed. ICSA-UFPA/Museu Paraense Emílio Goeldi: Belém, 2009, p. 83-94.

OLIVEIRA, José Aldemir de. Manaus de 19201967: a cidade doce e dura em excesso. Manaus: Valer/Edua/Governo do Amazonas, 2003.

ORLANDI, Eni P. Análise de Discurso: princípios e procedimentos. $8^{a}$ ed. Campinas: Pontes, 2009.

REIS, Arthur Cézar Ferreira. 0 impacto amazônico na civilização brasileira. Rio de Janeiro: Paralelo/ MEC, 1972.

ROCHA, Glauber. A destruição dos mitos (ou o paraíso perdido). In: GERBER, Raquel. 0 mito da civilização atlântica. Petrópolis: Vozes, 1982.

ROCHA, Glauber. Cartas ao mundo. Organização de Ivana Bentes. São Paulo: Companhia das Letras, 1997.

ROCHA, Glauber. Revolução do Cinema Novo. São Paulo: Cosac Naify, 2004.

STAM, Robert. Introdução à teoria do cinema. 5( ed. Campinas: Papirus, 2013.

VANOYE, Francis; GOLIOT-LÉTÉ, Anne. Ensaio sobre a análise fílmica. 7a ed. Campinas: Papirus, 2012.

VEnTURA, Tereza. Poética polytica de Glauber

Rocha. Rio de Janeiro: Funarte, 2000.

\section{SOBRE OS AUTORES}

Rosiel do Nascimento Mendonça é bacharel em Comunicação Social - Jornalismo (UFAM); especialista em Gestão Cultural pelo Centro
Universitário Senac; Mestre em Sociedade e Cultura na Amazônia (UFAM). Atua como jornalista cultural desde 2012, tendo experiência como repórter e editor nos cadernos Bem Viver e Vida\&Estilo do Jornal A Crítica, em Manaus. Como assessor de imprensa, tem experiência no segmento artístico independente, no setor público e em organizações não governamentais. Desde 2020, exerce o cargo de Produtor Cultural na Faculdade de Artes (Faartes) da UFAM. E-mail: rosielmendonca@gmail.com

Sérgio Ivan Gil Braga é licenciado em História (UFRGS); Bacharel em Ciências Jurídicas e Sociais (UFRGS); Mestrado em Antropologia Social (UFRGS); Doutor em Antropologia Social (USP). Desde 1991, é professor e pesquisador da Universidade Federal do Amazonas (UFAM). Professor Titular com Dedicação Exclusiva do Departamento de Antropologia, do Programa de Pós-Graduação em Antropologia Social e do Programa de PósGraduação Sociedade e Cultura na Amazônia da UFAM. E-mail: sigbraga@hotmail.com 